\title{
Removal of lead, copper, cadmium, zinc, and nickel from aqueous solutions by alkali-modified biochar: Batch and column tests
}

Zhuhong Ding ${ }^{\mathrm{a}, \mathrm{c}}$, Xin $\mathrm{Hu}^{\mathrm{b}, \mathrm{c}}$, Yongshan Wan ${ }^{\mathrm{d}}$, Shengsen Wang ${ }^{\mathrm{c}}$, Bin Gao ${ }^{\mathrm{c}, *}$

${ }^{a}$ School of Environment, Nanjing University of Technology, 30 Puzhu Southern Road, Nanjing 211816, P.R. China

${ }^{b}$ State Key Laboratory of Analytical Chemistry for Life Science, Center of Material Analysis, 20 Hankou Road, Nanjing University, Nanjing 210093, P.R. China

${ }^{c}$ Department of Agricultural and Biological Engineering, University of Florida, Gainesville, $F L$ 32611, United States

${ }^{d}$ Department of Soil and Water Science, University of Florida, Gainesville, FL 32611, United States

* Corresponding author. Tel.: (352) 392-1864x285; fax: (352) 392-4092. Email address: bg55@ufl.edu. 


\begin{abstract}
Engineered biochar was obtained through slow pyrolysis of hickory wood and then further modified with $\mathrm{NaOH}$. After modification, biochar's surface area, cation-exchange capacity, and thermal stability were significantly improved. The modified biochar exhibited much larger (2.6-5.8 times) metal adsorption capacities than the pristine biochar. Competitive batch adsorption of mixed metal ions $\left(\mathrm{Pb}^{2+}, \mathrm{Cd}^{2+}, \mathrm{Cu}^{2+}, \mathrm{Zn}^{2+}\right.$, and $\left.\mathrm{Ni}^{2+}\right)$ showed preferential adsorption of $\mathrm{Pb}^{2+}$ and $\mathrm{Cu}^{2+}$ onto the modified biochar. The alkali-modified biochar in a fixed-bed column also showed strong ability to filter heavy metals from aqueous solutions. The alkali-modified biochar thus can serve as alternative absorbent for heavy metals.
\end{abstract}

Keywords: sorption; filtration; engineered carbon; heavy metals; modified carbon 


\section{Introduction}

Biochar, a pyrogenic carbon material, recently has been regarded as a novel, low-cost alternative adsorbent for environmental remediation [1, 2]. The existing literature covers a wide range of studies on adsorption of different heavy metals onto biochars derived from various feedstocks including agricultural and forest residuals [3-7]. Most of these studies only employed batch experiments to examine of the sorption behaviors and mechanisms of aqueous heavy metals onto the biochars under optimal conditions. Relatively few studies were carried out with fixed-bed columns to determine the kinetic removal of aqueous heavy metals by biochar-based filters $[8,9]$.

Various modification methods have been developed in recent years to further enhance the sorption ability of biochars (i.e., engineered biochars). For example, magnetic biochars have been synthesized for the removal of aqueous arsenic, cadmium, lead [10-12]. Zhang and Gao [13] found that the presence of $\mathrm{AlOOH}$ nanoparticles on biochar surfaces can greatly its sorption of arsenic, methylene blue, and phosphate. Song et al. [14] and Wang et al. [15] found that MnOx-loaded biochars have enhanced sorption ability to aqueous copper and arsenic. Oxidation chemical agents such as hydrogen peroxide were also used to modify biochars to enhance their sorption ability to heavy metals in aqueous solutions $[8,16]$. All these modifications dramatically alter the surface properties of the biochars and greatly enhance their sorptive ability to heavy metals in aqueous solutions. This makes the engineered biochars more attractive for many environmental applications, particularly with respect to heavy metal remediation.

Alkali modification is another commonly used engineering method to improve the sorption ability of carbonaceous materials for their applications in wastewater treatment $[17,18]$. In comparison to other engineering methods such as acid and organic solvent modifications, alkali 
modification may be more effective in generating high BET surface area and altering surface functional groups [17]. Although this method should have great potential for biochar engineering, its effects on biochar's surface properties and sorption ability are still not well understood. This work used alkali $(\mathrm{NaOH})$ to modify biochar derived from hickory wood chips to improve its heavy metal sorption ability. The pristine and modified biochar samples were examined using thermogravimetric analyzer (TGA) and X-ray photoelectron spectroscopy (XPS). Other basic physicochemical properties of the biochars, such as elemental composition, surface area (SA), and cation exchange capacity (CEC), were also determined. In addition, both batch isotherm sorption and column filtration experiments were conducted to determine the sorptive ability of

the biochars to heavy metals (i.e., $\mathrm{Pb}^{2+}, \mathrm{Cd}^{2+}, \mathrm{Zn}^{2+}, \mathrm{Cu}^{2+}$, and $\mathrm{Ni}^{2+}$ ) in single and mixed metal systems. The regeneration of the spent biochar column was also investigated. The specific objectives of this work were to: 1 ) determine the effects of alkali modification on biochar's physiochemical properties; 2) measure the batch sorption isotherms of heavy metals onto the biochars in single and mixed metal systems; and 3) evaluate the performances of the modified biochar as filter media in fix-bed column to filtrate aqueous heavy metals.

\section{Materials and methods}

\subsection{Chemical reagents}

Chemical reagents of analytic grade including $\mathrm{NaOH}, \mathrm{HNO}_{3}, \mathrm{HCl}, \mathrm{Pb}\left(\mathrm{NO}_{3}\right)_{2}, \mathrm{Cu}\left(\mathrm{NO}_{3}\right)_{2}$, $\mathrm{Ni}\left(\mathrm{NO}_{3}\right)_{2}, \mathrm{CuCl}_{2}$, and $\mathrm{ZnCl}_{2}$ were purchased from Fisher Scientific. All solutions were prepared using deionized (DI) water $(18 \mathrm{M} \Omega * \mathrm{~cm})$.

\subsection{Biochar preparation and modification}


Hickory is one of the most common deciduous trees and distributed widely throughout the world. Hickory chips has been used as representative woody feedstock for biochar preparation in previous studies $[19,20]$. In this study, dried hickory chips were ground in a knife mill (Model No. 4, Arthur H. Thomas Company, Philadelphia, PA) to achieve 0.5-1 mm hickory powders. The powders were placed inside tubular quartz reactors $(50 \mathrm{~g}$ in $6 \mathrm{~cm}$ diameter $\times 28 \mathrm{~cm}$ cylinders $)$ inside a bench-top furnace (Barnstead $1500 \mathrm{M}$ / Olympic $1823 \mathrm{HE}$ ) purged with $\mathrm{N}_{2}$ gas (10 psi). The pyrolysis temperature of the furnace was ramped to $600^{\circ} \mathrm{C}$ at a rate of $20^{\circ} \mathrm{C} / \mathrm{min}$ and then held at this temperature for $2 \mathrm{~h}$. The produced biochar samples were washed with tap water and DI water several times, oven dried at $80^{\circ} \mathrm{C}$, and placed in a sealed container prior to use. The pristine biochar was notated as HB.

Alkali modification was carried out in a $100 \mathrm{~mL}$ Teflon bottle containing $10 \mathrm{~g} \mathrm{HB}$ and 20 $\mathrm{mL}$ of $5 \mathrm{M} \mathrm{NaOH}$ solution at $70^{\circ} \mathrm{C}$ for $4 \mathrm{~h}$. The resulting composite was dried at $110{ }^{\circ} \mathrm{C}$ and then heated to $600{ }^{\circ} \mathrm{C}$ inside a bench-top furnace (Barnstead $1500 \mathrm{M} /$ Olympic $1823 \mathrm{HE}$ ) purged with $\mathrm{N}_{2}$ gas (10 psi) for $2 \mathrm{~h}$. After cooled to room temperature, the resulting biochar was washed with tap water and $0.1 \mathrm{M} \mathrm{HCl}$ repeatedly until neutral $\mathrm{pH}$, then rinsed with DI water for several times, and finally dried at $110^{\circ} \mathrm{C}$ for $24 \mathrm{~h}$. The modified biochar was notated as HMB.

\subsection{Biochar characterization}

Contents of $\mathrm{C}, \mathrm{H}$ and $\mathrm{N}$ in the biochar samples were determined using a CHN Elemental Analyzer (Carlo-Erba NA-1500). Mineral elements were determined using inductively coupled plasma optical emission spectroscopy (ICP-OES, Perkin Elmer Optima 2100 DV, USA) after ashing at $550^{\circ} \mathrm{C}$ and acid dissolution. Surface areas were measured with a Quantachrome Autosorb-1 surface area analyzer using $\mathrm{N}_{2}$ (BET) sorption methods. Cation exchange capacity 
was analyzed using the US EPA SW-846 method 9081. The thermogravimetry (TG/DTG) curves were carried out using a Mettler TGA/DSC thermogravimetric analyzer (TGA/DSC 1, STARe System, METTLER TOLEDO, USA) at a heating rate of $10^{\circ} \mathrm{C} / \mathrm{min}$ from $50^{\circ} \mathrm{C}$ to $800^{\circ} \mathrm{C}$ under an atmosphere of oxygen $\left(50 \mathrm{~mL} \mathrm{~min}^{-1}\right)$. Surface elemental composition and elemental species were analyzed using XPS with a PHI 5100 series ESCA spectrometer (Perkin Elmer).

\subsection{Batch sorption}

Sorption isotherm experiments were carried out at room temperature $\left(20 \pm 2{ }^{\circ} \mathrm{C}\right)$ by adding $0.1 \mathrm{~g}$ biochars to $100 \mathrm{~mL}$ polyethylene centrifuge tubes containing $50 \mathrm{~mL}$ either single metal $\left(\mathrm{Pb}^{2+}\right)$ or mixed metal $\left(\mathrm{Pb}^{2+}, \mathrm{Cu}^{2+}, \mathrm{Zn}^{2+}, \mathrm{Ni}^{2+}\right.$, and $\left.\mathrm{Cd}^{2+}\right)$ solutions. The metal concentrations ranged from 2.0 to $250 \mathrm{mg} / \mathrm{L}$ for $\mathrm{Pb}^{2+}$ and from 2.0 to $100 \mathrm{mg} / \mathrm{L}$ for others $\left(\mathrm{Cd}^{2+}, \mathrm{Cu}^{2+}, \mathrm{Zn}^{2+}\right.$ and $\mathrm{Ni}^{2+}$ ). Initial $\mathrm{pH}$ of the metal solutions was adjusted to about 5.0 using $0.01 \mathrm{M} \mathrm{HCl}$ and $0.01 \mathrm{M}$ $\mathrm{NaOH}$. At this $\mathrm{pH}$, the metal ions in the solution are stable without precipitation. The mixture was shaken for $24 \mathrm{~h}$ in a rotary shaker to ensure a sorption/desorption equilibrium was reached (predetermined), and then centrifuged at $4000 \mathrm{rpm}$ for $10 \mathrm{~min}$. Concentrations of $\mathrm{Pb}^{2+}, \mathrm{Cu}^{2+}, \mathrm{Zn}^{2+}$, $\mathrm{Ni}^{2+}$, and $\mathrm{Cd}^{2+}$ in the supernatant were determined using ICP-OES (Optima 2300, Perkin-Elmer SCIEX, USA). In all cases, sorbed metal ions were calculated as the difference between the amount of each sorbate in the initial and final solutions.

\subsection{Column filtration and regeneration}

About $1.0 \mathrm{~g}$ of $\mathrm{HMB}$ was wet-packed as an interlayer in an acrylic column of $5 \mathrm{~mm}$ in diameter. Acid-cleaned quartz sand (0.5-0.6 mm average size) was used at each end of the column to help distribute the flow. The final height of the biochar layer in the column was about 
$1.55 \mathrm{~cm}$. The column was initially flushed with DI water for about $2 \mathrm{~h}$. A peristaltic pump (Masterflex L/S, Cole Parmer Instrument, Vernon Hills, IL) was used at the inlet (bottom) of the column to maintain an upward flow rate of $2 \mathrm{~mL} \mathrm{~min}^{-1}$. The filtration experiment was initiated by switching the influent to a mixed metal solution of $\mathrm{Pb}^{2+}, \mathrm{Cd}^{2+}, \mathrm{Cu}^{2+}, \mathrm{Zn}^{2+}$ and $\mathrm{Ni}^{2+}(100 \mathrm{mg} / \mathrm{L}$ for each at $\mathrm{pH}=5.0 \pm 0.2$ ) for $140 \mathrm{~min}$. The column was then flushed with DI water for another 120 $\min$.

After the column was flushed with DI water, the regeneration experiment was initiated by switching to $0.2 \mathrm{M} \mathrm{HCl}$ solution at the same flow rate for $120 \mathrm{~min}$. The filtration ability of the regenerated column was then evaluated by switching influent to single metal solution $\left(\mathrm{Pb}^{2+}, 150\right.$ $\mathrm{mg} / \mathrm{L}$ ) for $80 \mathrm{~min}$. The column was flushed with DI water for $70 \mathrm{~min}$ and then regenerated for the second time by flushing with acid solution again for $80 \mathrm{~min}$.

Effluent samples were collected every 2 min with a fraction collector (IS-95 Interval Sampler, Spectrum Chromatography, Houston, TX) and analyzed for metal concentrations by the ICP-OES.

\section{Results and discussion}

\subsection{Influences of alkali modification on biochar surface properties}

Alkali modification only had slight effects on the mineral element contents of the biochar (Table 1). The $\mathrm{Ca}$ and $\mathrm{Mg}$ contents were reduced, but the $\mathrm{Al}$ and $\mathrm{K}$ contents were increased, after the modification. This indicated that alkali treatment might have different effects on the minerals within the biochar structure: on one hand, it could leach some minerals (e.g., $\mathrm{Ca}$ and $\mathrm{Mg}$ ) out, but on the other hand, it could concentrate them (e.g., Al and K). Additional investigations are still needed to understand the controlling mechanisms of this phenomenon. The $\mathrm{C}$ and $\mathrm{N}$ contents of 
the HB were slightly higher than that of the HMB (Table 1). The alkali modification increased the $\mathrm{H}$ and $\mathrm{O}$ contents of the biochar from $1.83 \%$ to $2.25 \%$ and from $11.3 \%$ to $13.2 \%$, respectively. Atomic ratios of $\mathrm{H} / \mathrm{C}$ and $\mathrm{O} / \mathrm{C}$ were 0.26 and 0.10 for $\mathrm{HB}$ and 0.33 and $0.12 \mathrm{HMB}$. The slight increases in these atomic ratios in $\mathrm{HMB}$ are consistent with the relative enrichment of $\mathrm{O}$ and $\mathrm{H}$ and depletion of $\mathrm{C}$ and $\mathrm{N}$ with alkali modification, which may increase the presences of oxygen and hydrogen containing functional groups on the modified biochar surfaces $[7,21]$.

After the modification the surface area of the biochar increased dramatically (Table 1), which can be attributed to the interactions between $\mathrm{NaOH}$ and carbon matrix that increases porosity $[22,23]$. Furthermore, the alkali modification also tripled the CEC of the hickory biochar (Table 1). The BET surface area and the CEC of the HMB were $873.0 \mathrm{~m}^{2} \mathrm{~g}^{-1}$ and 124.5 $\mathrm{cmol} / \mathrm{kg}$, respectively, which are much larger than that of most pristine biochars reported in the literature $[2,19,24]$. The increased CEC of the modified biochar might be attributed to the increasing of surface oxygen containing functional groups (e.g., carboxyl and hydroxyl groups), which control biochar's CEC $[25,26]$. The significant increases in surface area and CEC after alkali modification suggested that HMB may offer more adsorption sites and electronegative surface for adsorption of heavy metals than HB.

TG/DTG curves exhibited slight mass loss in the temperature range of $50-100^{\circ} \mathrm{C}$ and then significant loss in about $250-600{ }^{\circ} \mathrm{C}$ (Fig. 1). The percentages of the final mass to the initial mass were $4.55 \%$ for $\mathrm{HB}$ and $6.09 \%$ for $\mathrm{HMB}$. It is reported that the mass loss in the range of $50-100^{\circ} \mathrm{C}$ reflects loss of moisture (water), then changes in surface functional groups in the range of $100-350^{\circ} \mathrm{C}$, and degradation of carbon skeletons at higher than $350^{\circ} \mathrm{C}$ [27]. The DTG curves exhibited a sharp peak and a broad peak for both HB and HMB in the range of about $200-600{ }^{\circ} \mathrm{C}$. The sharp peaks, which were about $-0.804 \% /{ }^{\circ} \mathrm{C}$ for $\mathrm{HB}$ and $-0.745 \% /{ }^{\circ} \mathrm{C}$ for $\mathrm{HMB}$, 
corresponded to about $362^{\circ} \mathrm{C}$ for $\mathrm{HM}$ and $415^{\circ} \mathrm{C}$ for $\mathrm{HMB}$. This enhanced thermal stability is indicative of potential changes of surface functional groups induced by alkali modification.

The XPS scan spectra indicated that the surface of biochars was comprised mainly of $\mathrm{C}$ and $\mathrm{O}$ with small amounts of $\mathrm{Si}(0.7 \%)$ in $\mathrm{HB}$ and $\mathrm{Si}(1.3 \%)$ and $\mathrm{Al}(6.3 \%)$ in $\mathrm{HMB}$ (Fig. 2). Surface C decreased from $86.7 \%$ in HB to $57.9 \%$ in HMB while surface O increased from $12.0 \%$ in $\mathrm{HB}$ to $33.3 \%$ in $\mathrm{HMB}$ (Fig. 2). Atomic ratios for surface $\mathrm{O} / \mathrm{C}$ were 0.14 for $\mathrm{HB}$ and 0.58 for $\mathrm{HMB}$, indicative of significant increase in surface O-containing functional groups with alkali modification. Similar results were also observed by $\mathrm{Hu}$ et al. [9] with an iron (Fe)-impregnated biochar. The dramatic increase of $\mathrm{Al}$ from 0 to $6.3 \%$ after modification suggested that alkali treatment exposed $\mathrm{Al}$ containing compounds on the biochar surface because the modified biochar only contained $0.66 \%$ of Al element (Table 1 ).

The high-resolution XPS spectrum further confirmed the change in surface properties of biochars with alkali modification (Fig. 3). The main peaks in $\mathrm{C}_{1 \mathrm{~s}}$ region were fitted at the peak binding energy of $284.81 \mathrm{eV}, 286.58 \mathrm{eV}$ and $288.80 \mathrm{eV}$ in $\mathrm{HB}$, and $283.34 \mathrm{eV}, 284.80 \mathrm{eV}, 286.11$ $\mathrm{eV}$ and $288.18 \mathrm{eV}$ in HMB (Fig. 3a). According to the XPS database of Thermo Scientific, the binding energy of $\mathrm{C}_{1 \mathrm{~s}}$ at $\sim 284.8 \mathrm{eV}$ can be assigned to $\mathrm{C}-\mathrm{C}$, at $\sim 286 \mathrm{eV}$ to organic $\mathrm{C}(\mathrm{C}-\mathrm{O}-\mathrm{C})$, and at $\sim 288.5 \mathrm{eV}$ to organic $\mathrm{C}(\mathrm{O}-\mathrm{C}=\mathrm{O})$. Therefore, amorphous $\mathrm{C}$ and/or graphite $\mathrm{C}$ at $\sim 284.8 \mathrm{eV}$ were the dominant species of $\mathrm{C}$ in the pristine and the modified biochars. Peaks at the binding energy of $\sim 288 \mathrm{eV}$ may be assigned to carboxylic, ester and lactone groups $(\mathrm{C}=\mathrm{O} /-\mathrm{C}=\mathrm{O})[28]$. A new peak in $\mathrm{HMB}$ at the binding energy of $283.34 \mathrm{eV}$ was assigned to $\mathrm{C}-\mathrm{H}$ (Fig. 3a) [28]. Compared to $\mathrm{HB}, \mathrm{C}$ or graphite, $\mathrm{C}$ in $\mathrm{HMB}$ decreased greatly while $\mathrm{C}-\mathrm{H}$ increased (Fig. 3a).

Only one peak was observed on the binding energy $\mathrm{O}_{1 \mathrm{~s}}$ region (Fig. 3b); yet an obvious shift was observed after alkali modification, indicating the presence of different chemical species of $\mathrm{O}$ 
in biochars [28]. The binding energy peak was at $533.11 \mathrm{eV}$ in $\mathrm{HB}$ and $531.86 \mathrm{eV}$ in $\mathrm{HMB}$ (Fig. 3b). The binding energy of $\mathrm{O}_{1 \mathrm{~s}}$ at $531.5-532 \mathrm{eV}$ can be assigned to organic $\mathrm{C}-\mathrm{O}$ and at $\sim 533 \mathrm{eV}$ to organic $\mathrm{C}=\mathrm{O}$. The shift in binding energy from a double bond in $\mathrm{HB}$ to a single bond in $\mathrm{HMB}$ suggested that alkali modification changed the surface $\mathrm{O}$ species. The overall change in surface properties with alkali modification, especially the surface O-containing functional groups, has direct implications in adsorption of heavy metals by the modified biochar [7, 29, 30].

\subsection{Isotherm sorption of metal ions onto biochars}

The competitive adsorption of $\mathrm{Pb}^{2+}, \mathrm{Cd}^{2+}, \mathrm{Cu}^{2+}, \mathrm{Zn}^{2+}$ and $\mathrm{Ni}^{2+}$ onto biochars in the initial concentration range of 2 to $100 \mathrm{mg} / \mathrm{L}$ was shown in Fig. 4. The equilibrium adsorption capacities of all the tested metals increased with increasing equilibrium concentration (Fig. 4). The equilibrium adsorption capacities of the HMB to the heavy metals in the mixed system were all about five times higher than that of the $\mathrm{HB}$, indicating that alkali modification greatly improved the metal removal ability of the modified biochar. The enhanced sorption of aqueous heavy metal by the modification biochar can be attributed to the facts that HMB showed much higher surface area, more oxygen containing surface functional groups, and higher CEC than the HB, as indicated by the characterization experiments. Several previous studies have demonstrated that surface area, surface functional groups, and CEC play important roles in controlling the sorption of heavy metals onto carbonaceous materials [2, 7, 31].

Despite the competitions, the biochars preferential sorbed $\mathrm{Pb}^{2+}$ and $\mathrm{Cu}^{2+}$ from the mixed metal solutions (Fig. 4). The sorption of $\mathrm{Zn}^{2+}$ by the biochars was much lesser; while $\mathrm{Cd}^{2+}$ and $\mathrm{Ni}^{2+}$ showed the lowest sorption. All the sorption isotherms were well-fitted by Langmuir isotherm models (all $R^{2}>0.85$ ). Langmuir adsorption capacities in HB and HMB in the mixed 
metal systems were 3.32 and $19.1 \mathrm{mg} / \mathrm{g}^{-1}$ for $\mathrm{Pb}^{2+}, 2.64$ and $17.9 \mathrm{mg} / \mathrm{g}$ for $\mathrm{Cu}^{2+}, 0.71$ and 1.83 $\mathrm{mg} / \mathrm{g}$ for $\mathrm{Zn}^{2+}, 0.20$ and $0.98 \mathrm{mg} / \mathrm{g}$ for $\mathrm{Cd}^{2+}$, and 0.24 and $0.89 \mathrm{mg} / \mathrm{g}$ for $\mathrm{Ni}^{2+}$ respectively.

In order to better understand the adsorption of heavy metals on the biochars, batch isotherm adsorption of single metal $\left(\mathrm{Pb}^{2+}\right)$ onto the pristine and the modified biochars was investigated (Fig. 5). As expected, alkali modification significantly increased the $\mathrm{Pb}^{2+}$ adsorption capacities of the hickory biochar because of the improvement in surface area, CEC, and surface functional groups. Since single metal solution was used, the adsorption isotherms of the two biochars were much higher than that in the mixed metal system (Fig. 4 and 5). The sorption isotherm data of single-metal test were fitted with the Langmuir model and simulations matched the isotherms well with the $R^{2}$ value of 0.942 for $\mathrm{HB}$ and 0.943 for HMB. Langmuir adsorption capacities of the biochars to $\mathrm{Pb}^{2+}$ were $11.2 \mathrm{mg} / \mathrm{g}$ for $\mathrm{HB}$ and $53.6 \mathrm{mg} / \mathrm{g}$ for HMB. A comparison of the maximum lead adsorption capacities of absorbents reported in the literature indicated that HMB matched or outperformed many other carbonaceous adsorbents (Table 2).

\subsection{Fixed-bed column adsorption and desorption study}

The breakthrough curves of $\mathrm{Pb}^{2+}, \mathrm{Cu}^{2+}, \mathrm{Cd}^{2+}, \mathrm{Zn}^{2+}$ and $\mathrm{Ni}^{2+}$ in the alkali-modified biochar column were different (Fig. 6a), which is consistent with the findings of batch sorption experiment that HMB selectively sorbed heavy metals from the mixed metal solutions. The sharp and immediate breakthrough curves of $\mathrm{Cd}^{2+}, \mathrm{Zn}^{2+}$, and $\mathrm{Ni}^{2+}$ in the column indicated that $\mathrm{HMB}$ had relatively low filtration ability to these contaminants in mixed metal system. Complete breakthrough (i.e., $\mathrm{Ct} / \mathrm{Co}=1$ ) for $\mathrm{Cd}^{2+}, \mathrm{Zn}^{2+}$, and $\mathrm{Ni}^{2+}$ occurred within 20 min, which is corresponding to the low Langmuir adsorption capacities determined in the batch experiment. In contrast, the elongated breakthrough curves of $\mathrm{Pb}^{2+}$ and $\mathrm{Cu}^{2+}$ in the column manifested their 
strong and preferential sorption onto HMB. As a fact, $\mathrm{Pb}^{2+}$ and $\mathrm{Cu}^{2+}$ in the column had not reached saturation during the 140 min filtration phase, indicating the alkali-modified biochar can be used as an effectively adsorbent to remove $\mathrm{Pb}^{2+}$ and $\mathrm{Cu}^{2+}$ from wastewater. The preferential adsorption of $\mathrm{Pb}^{2+}$ and $\mathrm{Cu}^{2+}$ over other metal ions has also observed for several other adsorbents $[32,33]$. This is mainly due to the fact that the two metal ions, especially $\mathrm{Pb}^{2+}$, have higher hydrolysis constants than that of the other metals to lower their degree of solvation and thus enabling them to better approach the solid surface for adsorption [33].

The regeneration of the adsorbent can minimize the cost of operation to improve process economics. The regeneration agent $(0.2 \mathrm{M} \mathrm{HCl})$ effectively released the sorbed heavy metals from the spent HMB column (Fig. 6b). The desorption curves exhibited a similar trend for all the sorbed metals with a sharp release peak followed by gradual decrease during the regeneration process. Similar pattern was observed in metal ions' desorption curves for carbonaceous adsorbents regenerated by acid or alkali $[9,34]$. The regeneration efficiency was the amount of $\mathrm{Pb}^{2+}$ mobilized from column by the $\mathrm{HCl}$ solution divided by the total amount of $\mathrm{Pb}^{2+}$ retained $(\mathrm{g} / \mathrm{g} ; \%)$. Mass balance calculation indicated that the regeneration efficiencies of the HMB by the acid were $100.6 \%$ for $\mathrm{Pb}^{2+}, 85.1 \%$ for $\mathrm{Cu}^{2+}, 46.3 \%$ for $\mathrm{Ni}^{2+}, 40.2 \%$ for $\mathrm{Zn}^{2+}$, and $34.7 \%$ for $\mathrm{Cd}^{2+}$, respectively. Although both the batch sorption and column filtration experiments indicated that HMB strongly and preferentially adsorbed aqueous $\mathrm{Pb}^{2+}$ and $\mathrm{Cu}^{2+}$, it can be regenerated by the acid for reuse, particularly with respect to the removal of $\mathrm{Pb}^{2+}$, likely for multiple times.

In the single-metal filtration system, the regenerated $\mathrm{HMB}$ column effectively removed $\mathrm{Pb}^{2+}$ from the solution (Fig. 7a). The column breakthrough curves showed a gradual increase and attained a value close to unity $(\mathrm{Ct} / \mathrm{C} 0=1)$ after $80 \mathrm{~min}($ Fig. $7 \mathrm{a})$. Due to the incomplete desorption of other metals, some adsorption sites of the HMB in the column were unavailable, resulting in 
decreased $\mathrm{Pb}^{2+}$ adsorption capacity in the regenerative column. Similarly, the $0.2 \mathrm{M} \mathrm{HCl}$ solution released most of the $\mathrm{Pb}^{2+}$ retained in the regenerated column with a desorption efficiency of $94.4 \%$ (Fig. 7b). These results suggested that the alkali-modified hickory biochar has great potential for application in treatment for heavy metals, particularly with respect to $\mathrm{Pb}^{2+}$.

\section{Conclusions}

This work showed that alkali $(\mathrm{NaOH})$ modification greatly increased the surface area, oxygen-containing surface functional groups, and CEC of biochar derived from hickory wood. As a result, the modified biochar showed much higher sorption of heavy metal ions (i.e., $\mathrm{Pb}^{2+}, \mathrm{Cd}^{2+}$, $\mathrm{Cu}^{2+}, \mathrm{Zn}^{2+}$ and $\mathrm{Ni}^{2+}$ ) than the original one in both single-metal and mixed-metal systems. In addition, fixed-bed column packed with the modified biochar showed good filtration of heavy metal ions and preferentially removed $\mathrm{Pb}^{2+}$ and $\mathrm{Cu}^{2+}$ out of the mixed-metal solution. The spent column was flushed with $0.2 \mathrm{M} \mathrm{HCl}$ solution, which desorbed all of the metal ions with $\mathrm{Pb}^{2+}$ desorption efficiency of $100.6 \%$. The regenerated column effectively removed $\mathrm{Pb}^{2+}$ from aqueous solution and most of the retained $\mathrm{Pb}^{2+}$ could be released by the acid solution. Findings from this work indicated that the alkali modification method can be applied to biochar to enhance its heavy metal removal ability and the resulting modified biochar has great potential as an alternative adsorbent for environmental remediation.

\section{Acknowledgment}

This work was partially supported by the Natural Science Foundation of China (21007026) and the NSF (CBET-1054405). Z. Ding acknowledges the support of the Jiangsu Overseas Research \& Training Program. 


\section{References}

[1] D. Mohan, A. Sarswat, Y.S. Ok, C.U. Pittman Jr, Bioresource Technol, 160 (2014) 191-202.

[2] M. Ahmad, A.U. Rajapaksha, J.E. Lim, M. Zhang, N. Bolan, D. Mohan, M. Vithanage, S.S. Lee, Y.S. Ok, Chemosphere, 99 (2014) 19-33.

[3] M. Inyang, B. Gao, Y. Yao, Y. Xue, A.R. Zimmerman, P. Pullammanappallil, X. Cao, Bioresource Technol, 110 (2012) 50-56.

[4] X.Y. Xu, X.D. Cao, L. Zhao, H.L. Wang, H.R. Yu, B. Gao, Environ Sci Pollut R, 20 (2013) 358-368.

[5] X.J. Tong, J.Y. Li, J.H. Yuan, R.K. Xu, Chem Eng J, 172 (2011) 828-834.

[6] M.D. Inyang, B. Gao, W.C. Ding, P. Pullammanappallil, A.R. Zimmerman, X.D. Cao, Separ Sci Technol, 46 (2011) 1950-1956.

[7] M. Uchimiya, S. Chang, K.T. Klasson, J Hazard Mater, 190 (2011) 432-441.

[8] Y. Xue, B. Gao, Y. Yao, M. Inyang, M. Zhang, A.R. Zimmerman, K.S. Ro, Chem Eng J, 200 (2012) 673-680.

[9] X. Hu, Z.H. Ding, A.R. Zimmerman, S.S. Wang, B. Gao, Water Res, 68 (2015) 206-216.

[10] D. Mohan, H. Kumar, A. Sarswat, M. Alexandre-Franco, C.U. Pittman, Chem Eng J, 236 (2014) 513-528.

[11] M. Zhang, B. Gao, S. Varnoosfaderani, A. Hebard, Y. Yao, M. Inyang, Bioresource Technol, 130 (2013) 457-462.

[12] S. Wang, B. Gao, A. Zimmerman, Y. Li, L. Ma, W. Harris, K. Migliaccio, Bioresource Technol, 175 (2015) 391-395.

[13] M. Zhang, B. Gao, Chem Eng J, 226 (2013) 286-292.

[14] Z.G. Song, F. Lian, Z.H. Yu, L.Y. Zhu, B.S. Xing, W.W. Qiu, Chem Eng J, 242 (2014) 36-42. 
[15] S.S. Wang, B. Gao, Y.C. Li, A. Mosa, A.R. Zimmerman, L.Q. Ma, W.G. Harris, K.W. Migliaccio, Bioresource Technol, 181 (2015) 13-17.

[16] Y.F. Xu, Z.J. Lou, P. Yi, J.Y. Chen, X.L. Ma, Y. Wang, M. Li, W. Chen, Q. Liu, J.Z. Zhou, J. Zhang, G.R. Qian, Bioresource Technol, 172 (2014) 212-218.

[17] B. Hayati, N.M. Mahmoodi, Desalin Water Treat, 47 (2012) 322-333.

[18] A. Bhatnagar, W. Hogland, M. Marques, M. Sillanpaa, Chem Eng J, 219 (2013) 499-511.

[19] Y. Sun, B. Gao, Y. Yao, J. Fang, M. Zhang, Y. Zhou, H. Chen, L. Yang, Chem Eng J, 240 (2014) 574-578.

[20] Y. Yao, B. Gao, H. Chen, L. Jiang, M. Inyang, A.R. Zimmerman, X. Cao, L. Yang, Y. Xue, H. Li, J Hazard Mater, 209 (2012) 408-413.

[21] A.B. Fuertes, M.C. Arbestain, M. Sevilla, J.A. Macia-Agullo, S. Fiol, R. Lopez, R.J. Smernik, W.P. Aitkenhead, F. Arce, F. Macias, Aust J Soil Res, 48 (2010) 618-626.

[22] M.A. Lillo-Rodenas, D. Cazorla-Amoros, A. Linares-Solano, Carbon, 41 (2003) 267-275.

[23] A. Robau-Sanchez, A. Aguilar-Elguezabal, J. Aguilar-Pliego, Micropor Mesopor Mat, 85 (2005) 331-339.

[24] K.A. Spokas, D.C. Reicosky, Annals of Environmental Science, 3 (2009) 179-193.

[25] C. Briggs, J.M. Breiner, R.C. Graham, Soil Sci, 177 (2012) 263-268.

[26] J. Lehmann, S. Joseph, Biochar for environmental management: Science and technology, Earthscan/James \& James, (2009).

[27] M. Zhang, B. Gao, Y. Yao, Y.W. Xue, M. Inyang, Sci Total Environ, 435 (2012) 567-572.

[28] V. Datsyuk, M. Kalyva, K. Papagelis, J. Parthenios, D. Tasis, A. Siokou, I. Kallitsis, C. Galiotis, Carbon, 46 (2008) 833-840.

[29] Z.H. Ding, X. Hu, A.R. Zimmerman, B. Gao, Bioresource Technol, 167 (2014) 569-573. 
[30] D. Mohan, C.U. Pittman Jr, M. Bricka, F. Smith, B. Yancey, J. Mohammad, P.H. Steele, M.F. Alexandre-Franco, V. Gómez-Serrano, H. Gong, J Colloid Interf Sci, 310 (2007) 57-73.

[31] M. Inyang, B. Gao, A. Zimmerman, M. Zhang, H. Chen, Chem Eng J, 236 (2014) 39-46.

[32] F. Pagnanelli, A. Esposito, L. Toro, F. Veglio, Water Res, 37 (2003) 627-633.

[33] Z. Reddad, C. Gerente, Y. Andres, P. Le Cloirec, Environ Sci Technol, 36 (2002) 2067-2073.

[34] U. Kumar, M. Bandyopadhyay, J Hazard Mater, (2006) 253 - 259.

[35] M. Sekar, V. Sakthi, S. Rengaraj, J Colloid Interf Sci, 279 (2004) 307-313.

[36] Z. Liu, F. Zhang, J Hazard Mater, 167 (2009) 933-939.

[37] W. Ding, X. Dong, M. Inyang, B. Gao, L.Q. Ma, Chemosphere, 105 (2014) 68-74.

[38] Y. Tian, B. Gao, V.L. Morales, L. Wu, Y. Wang, R. Munoz-Carpena, C. Cao, Q. Huang, L. Yang, Chem Eng J, 210 (2012) 557-563. 
Table 1. Elemental content, surface area (SA) and cation-exchange capacity (CEC) of the pristine and modified biochars.

\begin{tabular}{lllllllllll}
\hline & \multicolumn{10}{c}{ Elemental contents (\%) } \\
\cline { 2 - 8 } & $\mathrm{C}$ & $\mathrm{N}$ & $\mathrm{H}$ & $\mathrm{O}^{*}$ & $\mathrm{Ca}$ & $\mathrm{Mg}$ & $\mathrm{Al}$ & $\mathrm{K}$ & \\
\hline $\mathrm{HB}$ & 84.7 & 0.30 & 1.83 & 11.3 & 1.17 & 0.29 & 0.04 & 0.28 & 256 & 45.7 \\
$\mathrm{HMB}$ & 82.1 & 0.25 & 2.25 & 13.2 & 0.63 & 0.20 & 0.66 & 0.65 & 873 & 124.5 \\
\hline
\end{tabular}

*: Contents of $\mathrm{O}$ were obtained by the subtraction method

Table 2. Maximum lead adsorption capacities of various carbonaceous adsorbents

\begin{tabular}{llll}
\hline Adsorbent & $\begin{array}{l}\text { Adsorption capacity } \\
(\mathrm{mg} / \mathrm{g})\end{array}$ & Solution pH & References \\
\hline Activated carbon & 26.6 & 4.5 & Sekar et al. [35] \\
Oak biochar & 13.10 & 5.0 & Mohan et al. [30] \\
$\begin{array}{l}\text { Pinewood biochar } \\
\text { Rice husk biochars }\end{array}$ & $1.84-2.40$ & 5.0 & Mohan et al. [30] \\
$\begin{array}{l}\text { Pinewood biochars } \\
\text { Bagasse biochars }\end{array}$ & $3.89-4.25$ & 5.0 & Liu and Zhang [36] \\
$\begin{array}{l}\text { Pristine and modified } \\
\text { peanut hull hydrochar }\end{array}$ & 0.88 and 22.82 & 5.0 & Liu and Zhang [36] \\
Carbon nanotubes & $74.5-92.3$ & 5.0 & Ding et al. [37] \\
HB & 11.2 & 5.7 & Xue et al. [8] \\
HMB & 53.6 & 5.7 & Tian et al. [38] \\
\hline
\end{tabular}




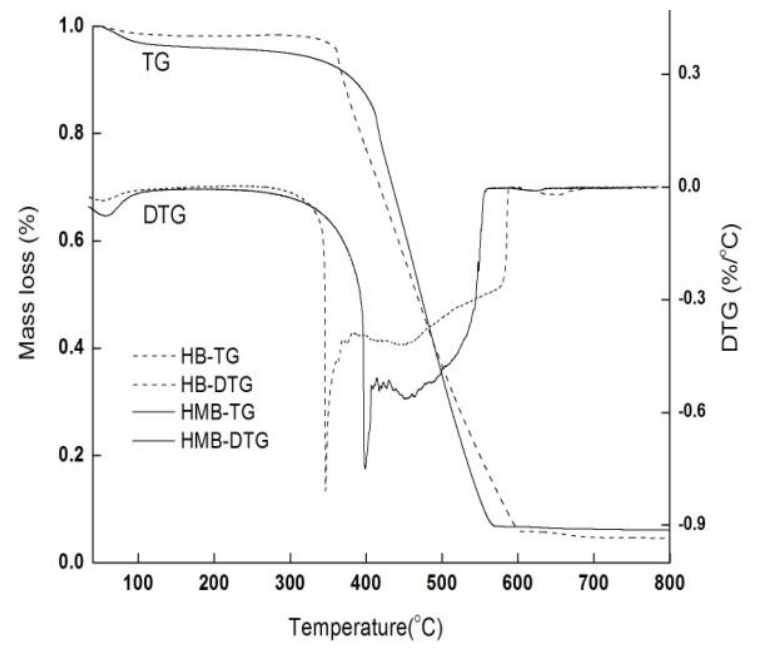

Fig. 1. TG-DTG curves of the biochars. 


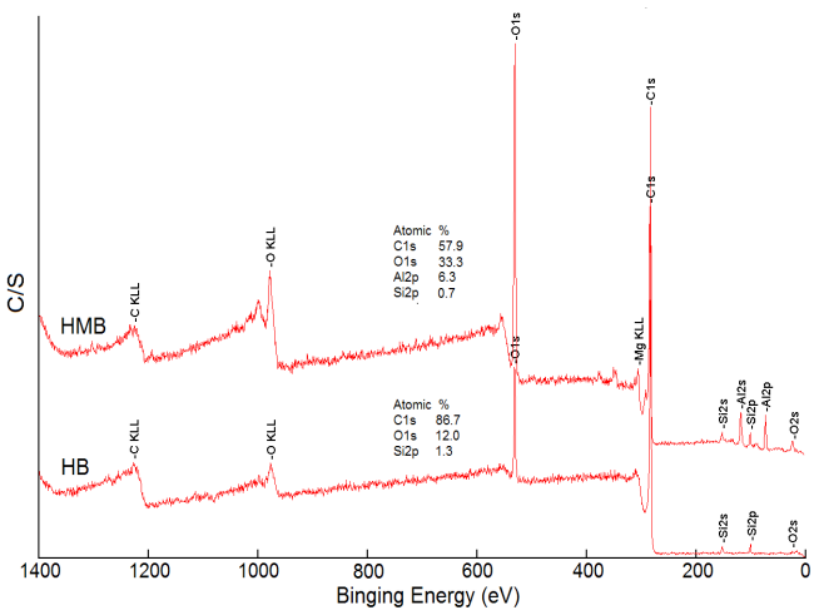

Fig. 2. XPS spectra of the biochars. 

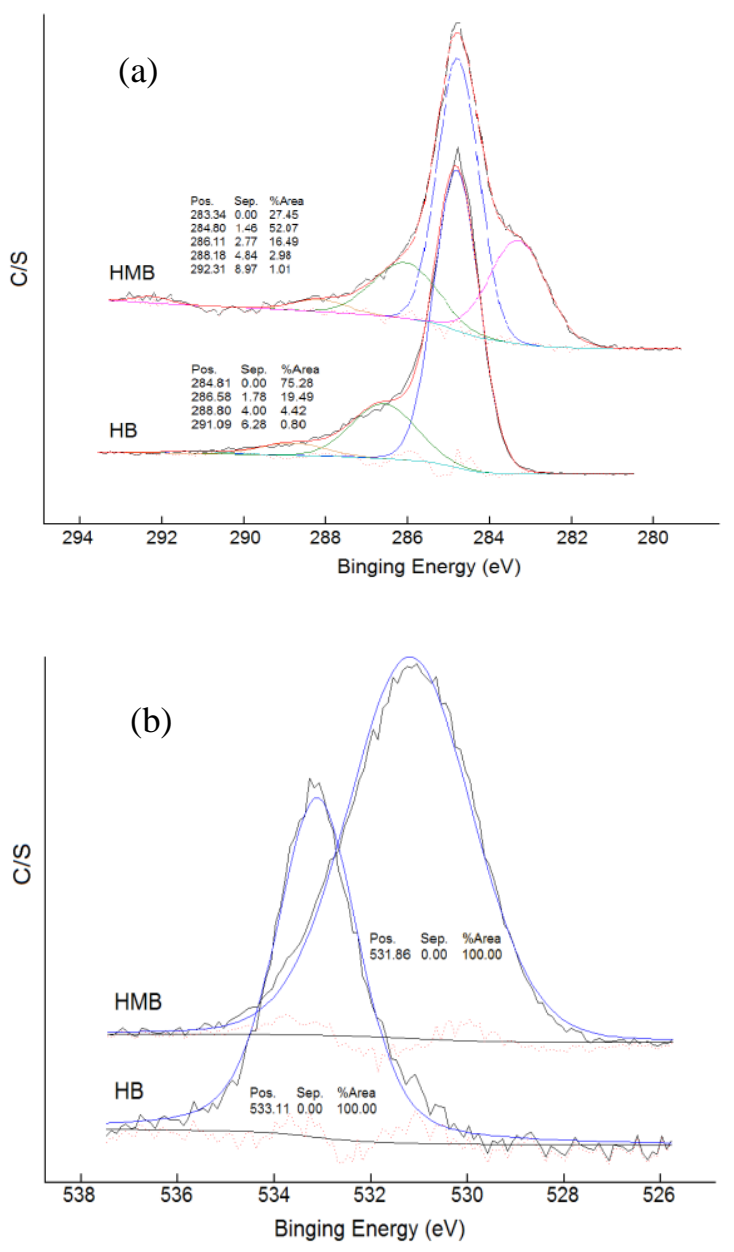

Fig. 3. High resolution XPS spectra of $\mathrm{C}_{1 \mathrm{~s}}(\mathrm{a})$ and $\mathrm{O}_{1 \mathrm{~s}}$ (b) in the biochars. 

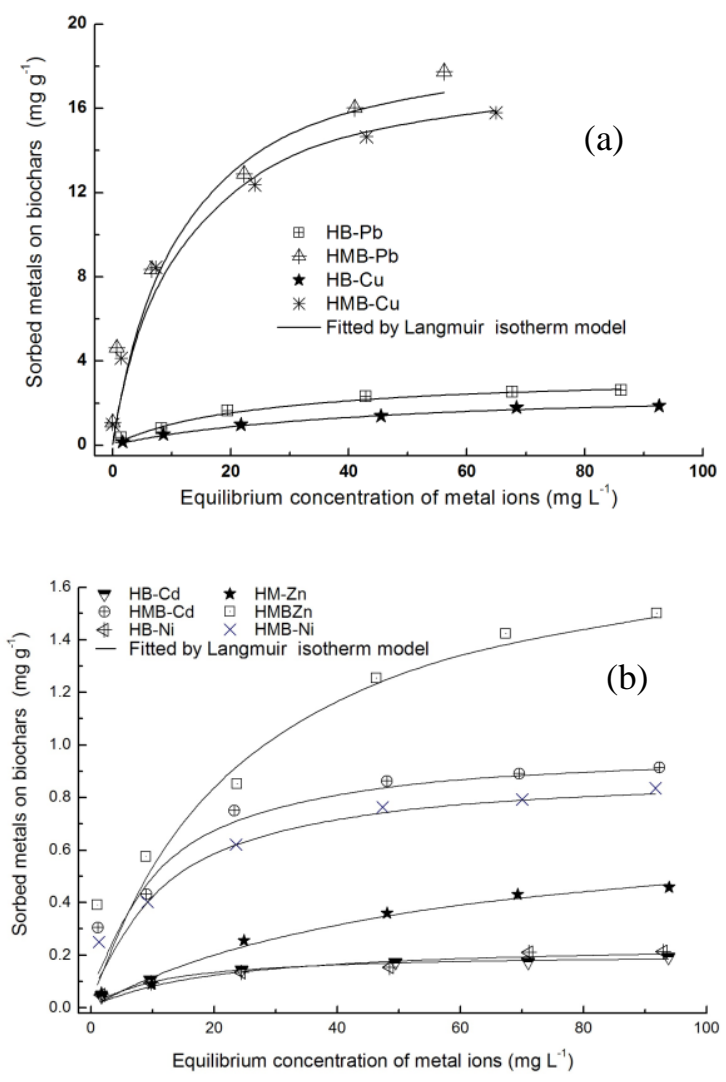

Fig. 4. Competitive sorption isotherms of heavy metals onto biochars: (a) $\mathrm{Pb}^{2+}$ and $\mathrm{Cu}^{2+}$ and (b) $\mathrm{Cd}^{2+}, \mathrm{Ni}^{2+}$, and $\mathrm{Zn}^{2+}$. Symbols are experimental data and lines are simulations from the Langmuir model. 




Fig. 5. Sorption isotherm of $\mathrm{Pb}^{2+}$ onto the biochars. Symbols are experimental data and lines are simulations from the Langmuir model. 

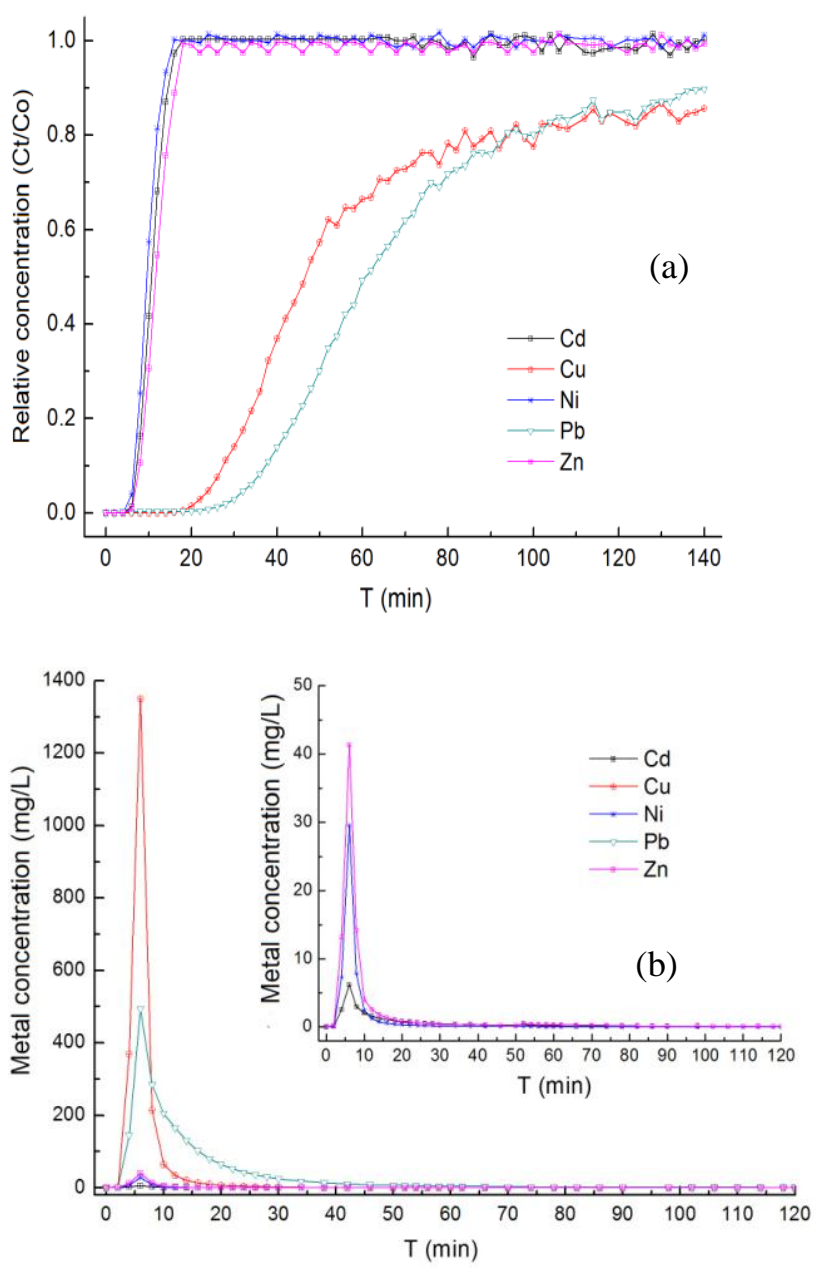

Fig. 6. Filtration of heavy metals in the fixed-bed HMB column: a) breakthrough curves after introducing the mixed metal solution and b) desorption curves after flushing with the acid solution. 



Fig. 7. Filtration of $\mathrm{Pb}^{2+}$ in the regenerated $\mathrm{HMB}$ column: a) breakthrough curves after introducing the $\mathrm{Pb}^{2+}$ solution and $\mathrm{b}$ ) desorption curves after flushing with the acid solution. 

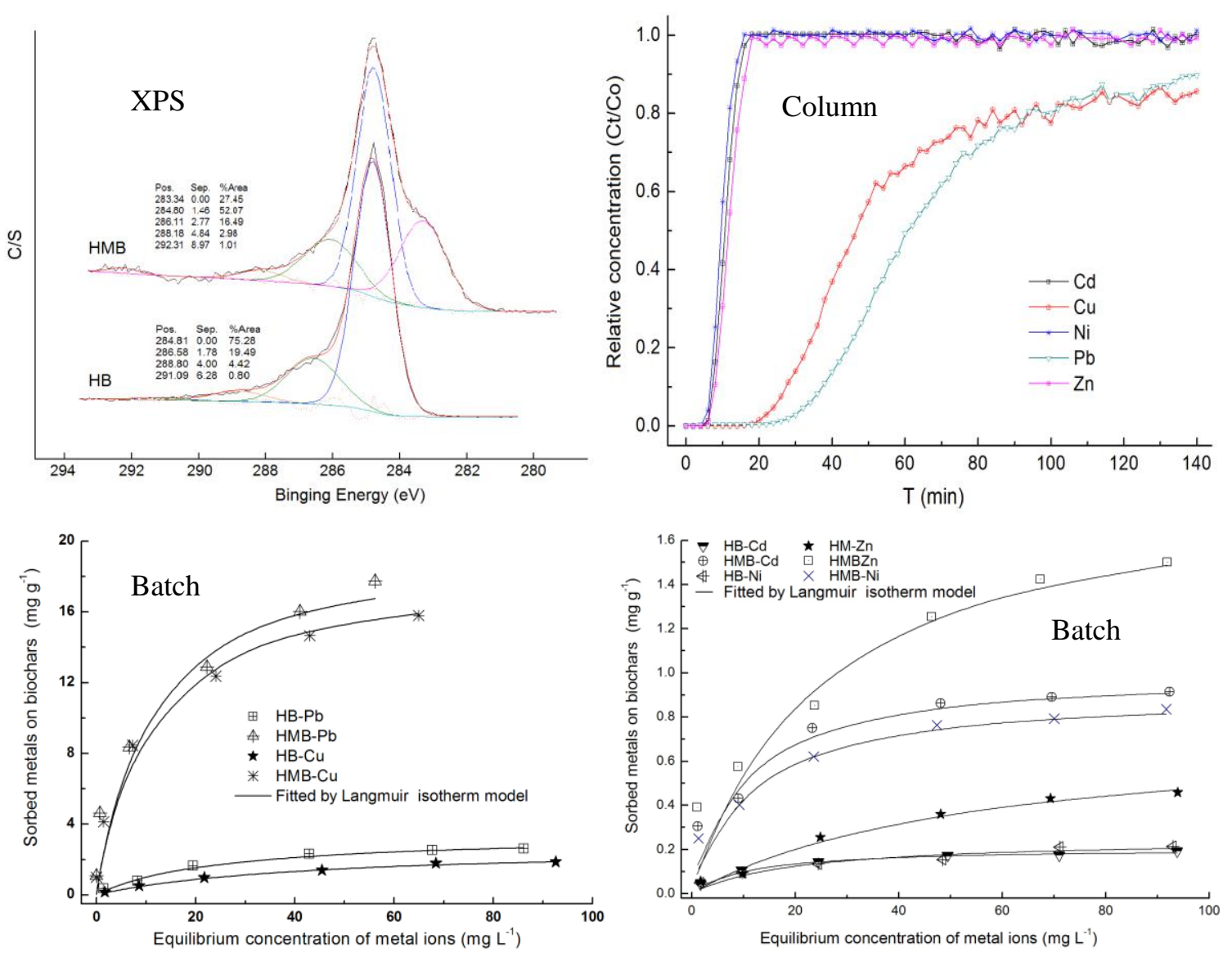